\title{
Erratum to: Role of maritime ports and shipping in the creation of the economic value of the sea areas
}

Jacek Zaucha ${ }^{1}$, and Maciej Matczak ${ }^{2}$

${ }^{1}$ University of Gdańsk, Faculty of Economics, 119/121 Armii Krajowej str., 81-824 Sopot, Poland

${ }^{2}$ Gdynia Maritime University, Faculty of Enterpreneurship and Quality Science, 81-87 Morska str., 81-225 Gdynia, Poland

Original article: SHS Web of Conferences 58, 01033 (2018), https://doi.org/10.1051/shsconf/20185801033

At the end of the paper, after Conclusions and before References should be added:

\section{Acknowledgement}

The paper presents the outcomes of the research financed by the Polish National Science Centre under the project "Economy of maritime space" (2015/17/B/HS4/00918). 